\title{
Effective microorganism fermentation extract (EM-X) attenuates airway hyperreactivity and inflammation through selective inhibition of the TH2 response independently of antioxidant activity
}

\author{
JEONG-SU DO, HYO-JUNG SEO, JIN-KI HWANG, JUN-HEE KIM and SANG-YUN NAM
}

Department of Biological Science, Jeonju University, Jeonju, Korea

Received May 7, 2007; Accepted July 16, 2007

\begin{abstract}
The effective microorganism fermentation extract (EM-X) is an antioxidant cocktail derived from the fermentation of plant material with effective microorganisms, and its clinical application is being increasingly scrutinized. In the current study, the antiasthmatic effect of EM-X was investigated using a mouse model. Inhalation of EM-X during OVA challenge resulted in a significant reduction in airway hyperreactivity (AHR) and airway recruitment of leukocytes including eosinophils. However, the level of 8-isoprostane in bronchoalveolar lavage fluid (BALF), a marker of oxidative stress in asthmatic patients, was unaltered by EM-X inhalation. Instead, ELISA data showed that levels of IL-4, IL-5 and IL-13 in BALF or lung tissues were significantly lower in EM-X-inhaling mice than in the control mice, but not the IFN- $\gamma$ level. A considerably lower amount of Ag-specific IgE and IgG1 was detected in the serum of EM-X-inhaling mice than in the serum of the controls, whereas their IgG2a secretion was similar. In addition, Ag-specific ex vivo IL-4, IL-5 and IL-13 production of draining lymph node cells was markedly diminished by EM-X inhalation, but not IFN- $\gamma$. These data clearly show that inhaled EM-X suppresses type 2 helper $\mathrm{T}$ (TH2), but not type 1 helper T (TH1), response. In conclusion, inhalation of EM-X attenuates AHR and airway inflammation which results from selective inhibition of the TH2 response to allergen, but independently of antioxidant activity. Our data also suggest that EM-X may be effectively applied for control of allergic asthma.
\end{abstract}

\section{Introduction}

Asthma is a major health problem worldwide. There is currently an epidemic of this disease in the western world,

Correspondence to: Professor Sang-Yun Nam, Department of Biological Science, Jeonu University, 3-1200 Hyoja-dong, Jeonu 560-759, Korea

E-mail: sangyun@jj.ac.kr

Key words: effective microorganism fermentation extract, airway hyperreactivity, inflammation, $\mathrm{TH} 2$ response, cytokine and its prevalence and severity have risen dramatically in recent decades $(1,2)$. Allergic asthma is a complex inflammatory disease of the airways characterized by reversible airflow obstruction (3) and is accompanied by chronic inflammation of the bronchial mucosa and a denudation of the epithelial lining of the bronchi and bronchioli (4).

Murine models of pulmonary inflammation and airway hyperresponsiveness have demonstrated that $\mathrm{CD}^{+}$type 2 helper $\mathrm{T}$ (TH2) cells play a pivotal role in allergic asthma. Being activated with allergen, they secrete cytokines which are involved in the production of $\operatorname{IgE}$ and the activation and airway recruitment of inflammatory leukocytes (5). This knowledge has come from extensive investigation showing that depletion of $\mathrm{CD} 4{ }^{+} \mathrm{T}$ cells and neutralization of $\mathrm{TH} 2$ cytokines abolishes allergic asthma in mouse models (6-9). Activated eosinophils are another major source of multiple TH2 cytokines which are known mediators of asthma (1013). Of those, IL-4 is crucial for TH2 development and induction of $\operatorname{IgE}$ synthesis $(14,15)$, and IL-5 regulates eosinophil activation, recruitment and maturation in the bone marrow (16-18). IL-13 has very similar biological activities to IL-4 (19), although their action in T cell proliferation and differentiation is distinctly displayed, that is, directly by IL-4 (20) or indirectly by IL-13 (21).

Oxidative stress, an imbalance between reactive oxygen species and the body's defense system, has also been described as a pathological mediator in allergic asthma. Oxidative stress associated with a large variety of reactive oxygen species plays an important role in airway inflammation through epithelial cell damage and the loss of cellular integrity $(22,23)$. Although profound insights have been made into the pathology of asthma so far, the exact mechanisms inducing and regulating the disease still remain elusive.

The effective microorganism fermentation extract (EM-X) is a refreshment drink, and it is produced by fermentation of unpolished rice, papaya, and seaweed with effective microorganisms including photosynthetic bacteria, lactic acid bacteria and yeast (24). EM-X inhibits in vitro growth and reduces the regenerative potential of cancer cells (25). EM-X also in vivo protects the liver and kidney from oxidative stress-dependent damage (26) and shows anti-inflammatory (27) and neuroprotective effects for retinal (28) and dopaminergic neurons (29). Although the underlying mechanisms 
are unclear, accumulated evidence shows that the antioxidant properties displayed by flavonoids, saponins, ubiquinones, lycopene and vitamin E are most probably associated with the activities of EM-X $(26,27,30)$. Despite a recently increasing number of reports on the clinical use of EM-X, its antiasthmatic action has never been described. Here, we report conclusive evidence showing the potential of EM-X for clinical use to prevent or control asthma and other allergic diseases by selective suppression of the $\mathrm{TH} 2$ response but independently of antioxidant activity.

\section{Materials and methods}

Animals. Female BALB/c 5- to 6-week-old mice were supplied from Samtaco (Osan, Korea), the Korean branch of Taconics (Germantown, NY). The mice were maintained in an environmentally controlled rearing system and used for experiments when 7- to 8-weeks old. Mice were age-matched for each experiment, and all experiments in this study were performed in accordance with Jeonju University Institutional Animal Care and Use Committee guidelines.

Induction of allergic airway inflammation. All mice were sensitized and challenged with OVA (chicken egg albumin, grade V; Sigma, St. Louis, MO). Systemic sensitization was performed by two i.p. injections of $50 \mu \mathrm{g}$ OVA absorbed to $1 \mathrm{mg}$ alum (aluminum ammonium sulfate, Sigma) in $0.3 \mathrm{ml}$ PBS (phosphate-buffer saline, $\mathrm{pH}$. 7.4) on days 0 and 7. On days 15, 16 and 18, mice were anesthetized by i.p. injection of Avertin (2.5\% wt/vol in PBS) and intranasally challenged with $2 \%$ OVA in PBS (50 $\mu 1 /$ mouse).

EM-X and treatment. EM-X was kindly supplied by EM Korea (Jeonju, Korea). Mice inhaled aerosol containing 16fold diluted EM-X in PBS with a nebulizer (Schuco 2000, Allied Health Care Products, St. Louis, MO) from day 14 for 5 consecutive days.

Measurement of airway hyperreactivity (AHR). AHR was measured $24 \mathrm{~h}$ after the last OVA challenge (day 19), by recording respiratory pressure curves in response to inhaled nebulized methacholine (acetyl- $\beta$-methylcholine chloride; Sigma) using whole-body plethysmography (All-Medicus, Seoul, Korea) as previously described (31). AHR was expressed in enhanced pause (Penh), an index of airway obstruction. Penh values were obtained for $5 \mathrm{~min}$ and averaged. Mice were exposed to a series of methacholine aerosols $(0,6.25,12.5,25$ and $50 \mathrm{mg} / \mathrm{ml})$.

Analysis of BALF (bronchoalveolar lavage fluid). BALF was obtained immediately after bleeding of the mice by lavage of the airways through a tracheal cannula with PBS. For differential BALF cell counts, cytospin preparations were made $(1,000 \mathrm{rpm}, 5 \mathrm{~min})$ using a cytocentrifuge (Shandon Southern Products, Runcorn, Cheshire, UK) and stained with Diff-Quick (Baxter Healthcare, Miami, FL). For each cytospin preparation, a minimum of 500 cells was counted and differentiated into macrophages, eosinophils, neutrophils and lymphocytes by morphology and staining characteristics.
Collection of serum. After mice were anesthetized, blood was extracted by cardiac puncture. Blood was allowed to clot at room temperature for $30 \mathrm{~min}$, and the serum recovered by centrifugation $\left(10,000 \mathrm{rpm}, 5 \mathrm{~min}\right.$ at $\left.4^{\circ} \mathrm{C}\right)$ was stored at $70^{\circ} \mathrm{C}$ until use.

Preparation of peribronchial lymph node (LN) cells. The LN cells were derived from the paratracheal and parabronchial regions. Freshly isolated LN cells were made into single-cell suspensions, and contaminated erythrocytes were lysed by hypotonic shock with sterile distilled water. Cells were stimulated with OVA $(200 \mu \mathrm{g} / \mathrm{ml})$ at $1 \times 10^{6}$ cells $/ \mathrm{ml}$ in IMDM medium (Gibco Laboratories, Grand Island, NY) supplemented with $10 \%$ heat-inactivated FBS (Gibco), $100 \mathrm{U} / \mathrm{ml}$ penicillin, $100 \mu \mathrm{g} / \mathrm{ml}$ streptomycin, $0.25 \mu \mathrm{g} / \mathrm{ml}$ amphotericin B (Sigma) and $5 \times 10^{-5} \mathrm{M}$ 2-mercaptoethanol (2ME).

Enzyme-linked immunosorbent assay (ELISA). The levels of the cytokines in the culture supernatants and $\mathrm{Ig}$ in the serum were determined in appropriate dilutions by sandwich ELISA using antibody pairs against murine IFN- $\gamma$, IL-2, IL-5 (Biosource), IL-4 (BioLegend) and IgE, IgG1 and IgG2a (BD Pharmingen) following the manufacturer's instructions.

8-isoprostane assay. The levels of 8-isoprostane in BALF were determined by competitive ELISA (Cayman Chemical, Ann Arbor, MI) according to the the manufacturer's recommendations.

Statistical analysis. Statistical analysis and graphical presentation were conducted using SigmaPlot 6.0 (SPSS Inc., Chicago, IL). Values were provided as the means \pm SE, and group means were compared with the Student's t-test in which $\mathrm{p}<0.05$ was considered significant.

\section{Results}

EM-X inhalation attenuates AHR in a mouse model of asthma. To examine the effect of EM-X in the development of allergen-induced AHR and lung inflammation, we sensitized and challenged mice with OVA. As shown in Fig. 1, control mice developed significant AHR, however, the Penh values in EM-X-inhaling mice, sensitized and challenged in the same manner, were significantly lower than in the control mice when they were elicited with increasing concentrations of methacholine. Significant differences in Penh value were shown at 25 and $50 \mathrm{mg} / \mathrm{ml}$ methacholine $(\mathrm{p}<0.05, \mathrm{n}=12)$. These results show that EM-X exerts an inhibitory effect on AHR in asthmatic mice.

EM-X inhalation suppresses lung inflammation. To validate that EM-X also effectively reduces lung inflammation, the airway recruitment of leukocytes was analyzed. The total number of leukocytes in BALF was severely decreased in EM-X-inhaling mice $\left(2.2 \pm 0.3 \times 10^{5}\right.$ cells $\left./ \mathrm{ml}\right)$, when compared to those in BALF of the control mice $\left(5.2 \pm 0.3 \times 10^{5}\right.$ cells $/ \mathrm{ml}$; $\mathrm{p}<0.01, \mathrm{n}=10$ ) (Fig. 2A), and the absolute numbers of leukocyte subpopulations were also significantly reduced (Fig. 2B). 


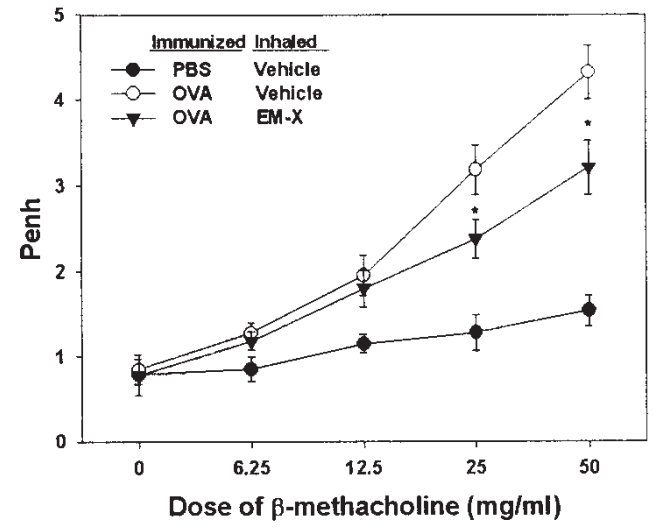

Figure 1. Effect of EM-X inhalation on airway hyperreactivity in a mouse model of asthma. Mice were sensitized with OVA at days 0 and 7, and then intranasally challenged with OVA on days 15,16 and 18. Control mice underwent the same procedure but received PBS instead of OVA. Aerosolized EM-X was administered from day 14 for 5 consecutive days. One day after last challenge, Penh was determined in response to increasing doses of methacholine. Data are shown as the cumulative means \pm SE of 12 individual mice from 4 independent experiments. ${ }^{*} \mathrm{p}<0.05$ vs each control (OVA/Vehicle)
(A)

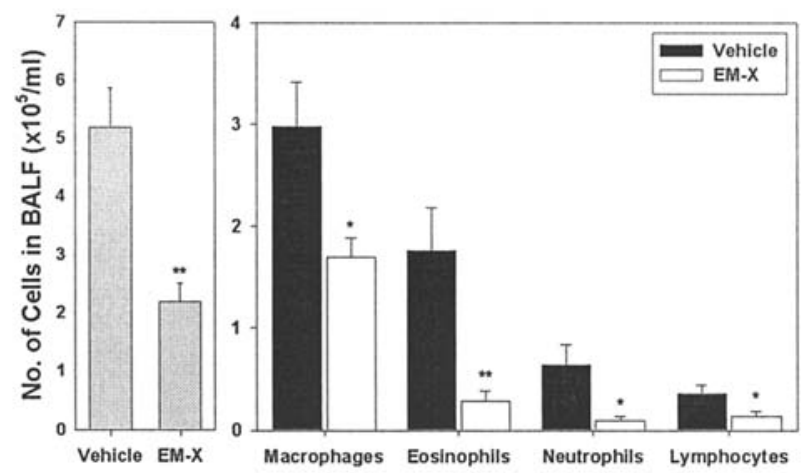

Figure 2. Effect of EM-X inhalation on airway inflammation in a mouse model of asthma. Mice were immunized and EM-X was administered as described in Fig. 1. After examination of AHR, the trachea was cannulated and the lungs were lavaged. Total number of viable leukocytes (A) in recovered BALF was enumerated, and differential cell counts (B) were performed on Diff-Quik-stained cytocentrifuge preparations. Data are shown as the cumulative means \pm SE of 10 individual mice from 3 independent experiments. ${ }^{*} \mathrm{p}<0.05$ and ${ }^{* *} \mathrm{p}<0.01$ vs vehicle control.

EM-X inhalation exerts an antiasthmatic effect independently of antioxidant activity. EM-X is well known as an antioxidant cocktail, and the antiasthmatic activity of EM-X may be attributed to its antioxidant action. To address this issue, we analyzed the level of 8-isoprostane in BALF, a marker of oxidative stress in asthmatic patients (32). The level of 8isoprostane in BALF was considerably increased by OVA challenge (from $6.2 \pm 0.9$ to $57.7 \pm 8.1 \mathrm{pg} / \mathrm{ml} ; \mathrm{p}<0.01, \mathrm{n}=10$ ). However, EM-X inhalation resulted in no significant difference (45.8 $\pm 5.1 \mathrm{pg} / \mathrm{ml}$ ) (Fig. 3), suggesting that the antiasthmatic effect of EM-X is uncoupled with its antioxidant activity.

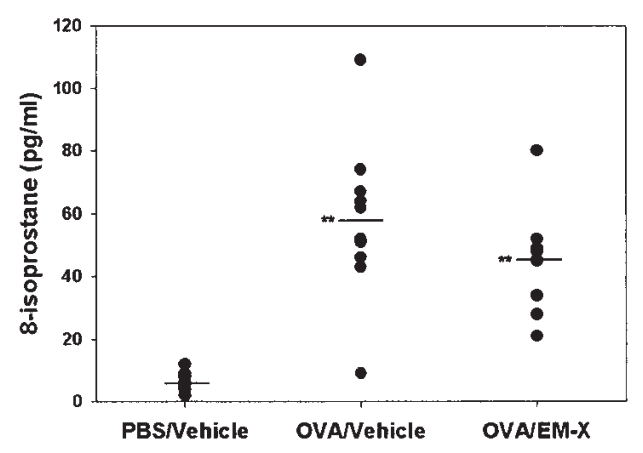

Figure 3. Effect of EM-X inhalation on the level of 8-isoprostane in BALF. BALF was recovered from non-immunized and asthmatic mice as described in Fig. 2, and levels of 8-isoprostane were determined by competitive ELISA. Data are shown as the cumulative means \pm SE of 10 individual mice from 3 independent experiments. ${ }^{* *} \mathrm{p}<0.01 \mathrm{vs}$ the control (PBS/Vehicle).
(A)

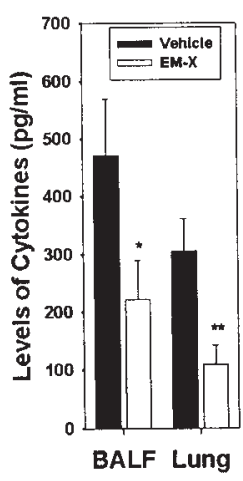

(B)

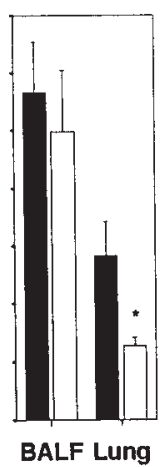

(C)

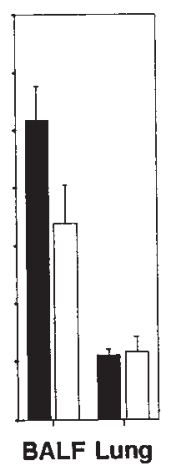

(D)

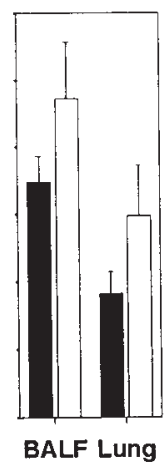

Figure 4. Effect of EM-X inhalation on the cytokine levels in BALF. BALF and lung homogenate were recovered 1 day after last challenge, and levels of IL-4 (A), IL-5 (B), IL-13 (C) or IFN- $\gamma$ (D) were determined by ELISA. Data are shown as the cumulative means \pm SE of 10 individual mice from 3 independent experiments. ${ }^{*} \mathrm{p}<0.05$ and ${ }^{* *} \mathrm{p}<0.01$ vs vehicle control.

EM-X inhalation diminishes type 2 cytokine and Ig levels in vivo. The above results allow us to hypothesize that EM-X inhalation leads to immune modification suppressing the allergic response. To clarify this hypothesis, we evaluated in vivo levels of relevant cytokines. The levels of IL-5, IL-13 and IFN- $\gamma$ in BALF of the controls were not significantly different from those of EM-X-inhaling mice. However, the level of IL-4 in EM-X-inhaling mice was only half $(221.2 \pm 68.4 \mathrm{pg} / \mathrm{ml})$ of that in the control mice $(471.7 \pm 97.4 \mathrm{pg} /$ $\mathrm{ml} ; \mathrm{p}<0.05, \mathrm{n}=10)$. While the levels of IL-13 and IFN- $\gamma$ in the lung tissues were comparable between the two groups, IL-4 (108.0 $\pm 33.4 \mathrm{pg} / \mathrm{ml})$ and IL-5 $(126.4 \pm 15.4 \mathrm{pg} / \mathrm{ml})$ levels in EM-X-inhaling mice were significantly lower than those of the control mice (IL-4, 304.6 $\pm 56.0, \mathrm{p}<0.01$; IL-5, 282.1 $\pm 59.4 \mathrm{pg} /$ $\mathrm{ml}, \mathrm{p}<0.05, \mathrm{n}=10$ ) (Fig. 4)

To assess the efficacy of EM-X on the Ag-specific humoral immune response, OVA-specific Ig levels in serum were measured. As shown in Fig. 5, markedly lower levels of OVAspecific IgE and IgG1 were observed in the serum of EM-Xinhaling mice (Fig. 5A and B), whereas their IgG2a secretion was similar (Fig. 5C). 
(A)

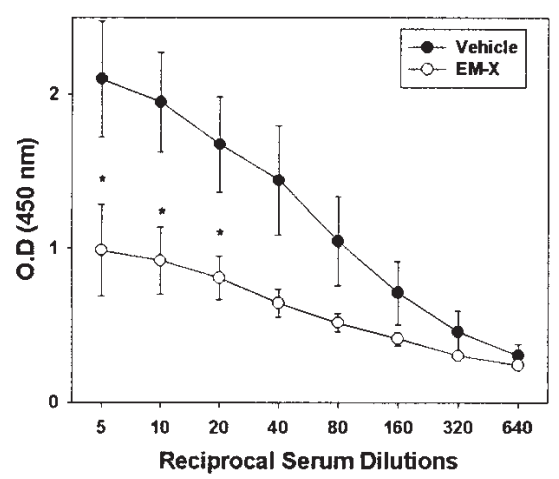

(B)

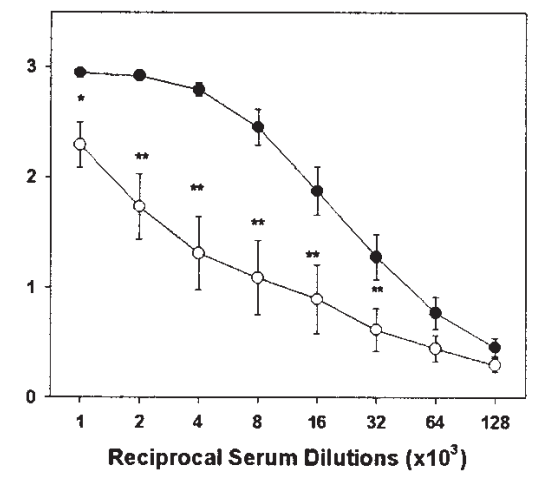

(C)

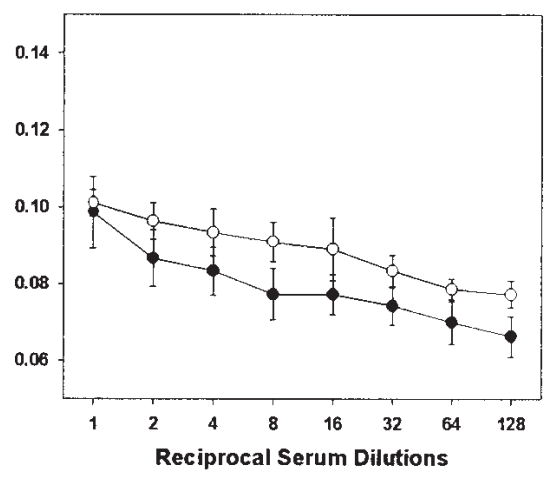

Figure 5. Effect of EM-X inhalation on Ag-specific antibody secretion in vivo. After examination of airway lavage, blood was taken by cardiac puncture and serum was recovered. Ag-specific serum $\operatorname{IgE}(\mathrm{A}), \operatorname{IgG} 1$ (B) and $\operatorname{IgG} 2 \mathrm{a}(\mathrm{C})$ levels were evaluated by ELISA. Data are shown as the cumulative means \pm SE of 6 individual mice from 3 independent experiments. ${ }^{*} \mathrm{p}<0.05$ and ${ }^{* *} \mathrm{p}<0.01$ vs each control.

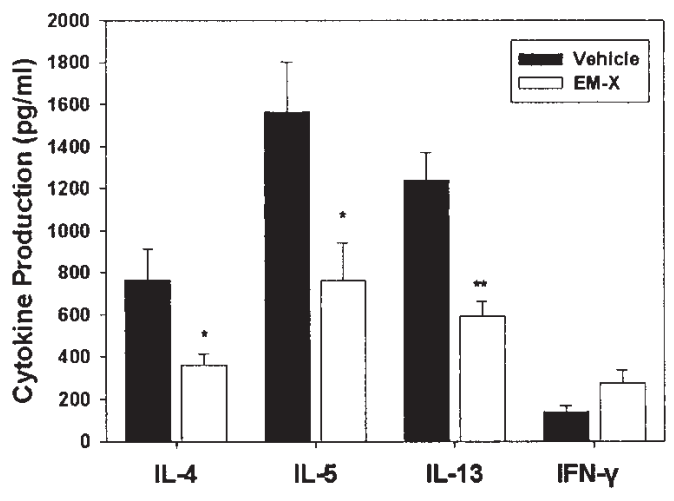

Figure 6. Effect of EM-X inhalation on Ag-specific cytokine production of lymph node cells. One day after last challenge, peribronchial LN cells were prepared and stimulated with OVA for 3 days, and their ex vivo cytokine production was examined by ELISA. Data are shown as the cumulative means \pm SE of 12 individual mice from 4 independent experiments. ${ }^{*} \mathrm{p}<0.05$ and ${ }^{* *} \mathrm{p}<0.01$ vs each control.

EM-X inhalation suppresses Ag-specific type 2 cytokine production by peribronchial lymph node cells. Data in Fig. 4 clearly show that EM-X selectively suppresses the TH2 response. To further evaluate this effectiveness, we assayed ex vivo Ag-specific cytokine production of draining lymph node cells. The numbers of peribronchial LN cells were not greatly different (data not shown), demonstrating that EM-X does not act as a booster for Ag-specific proliferation of lymphocytes. However, their capacity to produce ex vivo TH2 cytokines such as IL-4 (765.8 \pm 145.4 vs. $360.4 \pm 55.4$ pg/ $\mathrm{ml}, \mathrm{p}<0.05)$, IL-5 (1563.4 \pm 239.3 vs. $761.1 \pm 178.8 \mathrm{pg} / \mathrm{ml}$, $\mathrm{p}<0.05)$ and IL-13 (1238.5 \pm 132.7 vs. $591.5 \pm 68.3 \mathrm{pg} / \mathrm{ml}$, $\mathrm{p}<0.01)$ was diminished by half when EM-X was inhaled, whereas IFN- $\gamma$ production was increased without significance (Fig. 6).

\section{Discussion}

Effective microorganism-X is a refreshment drink developed in Japan (24), and the potential of EM-X for clinical application has been validated by recent reports showing an in vivo protective effect on the liver and kidney (26) as well as anti-inflammatory (27) and neuroprotective effects $(28,29)$. Recently, clinical application for the treatment of cancer and several intractable diseases is being increasingly scrutinized (33). However, published data addressing the antiasthmatic effect of EM-X are still unavailable. In the current study, using a mouse model, we investigated whether in vivo $\mathrm{EM}-\mathrm{X}$ treatment reduces allergic asthma.

Our data clearly showed that EM-X attenuates the allergic response upon analysis of AHR and leukocyte recruitment into airways (Figs. 1 and 2). Inasmuch as the antioxidative potential has been well documented as a major action of EM-X, antioxidation was implicated as a mechanism underlying the antiasthmatic activity of EM-X. As a target molecule to test the antioxidative outcome related with asthmatic responses, 8-isoprostane appeared the most likely candidate. It is a marker of oxidative stress in asthmatic patients (32), and its concentrations are elevated during acute asthma and decrease with recovery (34). However, analysis of the level of 8-isoprostane in BALF revealed no difference between the EM-X-inhaling and control groups (Fig. 3). This result suggests that the antiasthmatic activity of EM-X is uncoupled with antioxidative activity.

On the other hand, inhalation of EM-X resulted in a marked decrease in the $\mathrm{TH} 2$ response. EM-X inhalation decreased the in vivo secretion of IL-4 and IL-5 (Fig. 4) and OVA-specific IgE and IgG1 (Fig. 5) as well as ex vivo IL-4, IL-5 and IL-13 production of OVA-stimulated LN cells (Fig. 6). One possible explanation for the failure to show a significant decrease in all TH2 cytokine levels in BALF is that protein quantity is variably detected depending on consumption by responding cells or decay under the local environment. Clinical and experimental investigations have confirmed that allergen-specific CD4 ${ }^{+}$TH2-type cells $(35,36)$ and the cytokines IL-4 (14,15), IL-5 (16-18) and IL-13 (19) play central roles in initiating and sustaining an asthmatic response by regulating the recruitment and/or activation of airway mast cells and eosinophils. Our data in the present study strongly affirms that EM-X inhalation attenuates allergic manifestations through selective inhibition of the 
TH2 response and also suggest a therapeutic potential of EM-X against other allergic diseases.

Despite intensive studies on pathogenesis as well as therapy, asthma remains an increasingly prevalent disease of the industrialized nations $(1,2)$. Yet, current asthma therapies are not cures, and only pharmacological control of asthmatic symptoms is being achieved in most asthmatics with antiinflammatory agents (37) and/or long-acting bronchodilators $(1,38)$. Therefore, there is the obvious need for a new therapy for severe asthma, and the use of EM-X as a TH2-suppressing reagent for immunotherapy in allergic diseases is likely to have great potential.

The active mechanism of EM-X is only beginning to be understood. Several lines of evidence have shown that the clinical efficacy of EM-X is largely attributed to the antioxidant properties displayed by flavonoids, saponins, ubiquinones, lycopene and vitamin E $(26,27,30)$. The identification of the active component(s) responsible for the antiasthmatic activity in EM-X will indeed extend its clinical potential for treatment of related diseases.

\section{References}

1. ISAAC: Worldwide variation in prevalence of symptoms of asthma, allergic rhinoconjunctivitis, and atopic eczema; ISAAC. The International Study of Asthma and Allergies in Childhood (ISAAC) Steering Committee. Lancet 351: 1225-1232, 1998.

2. Umetsu DT, McIntire JJ, Akbari O, Macaubas C and DeKruyff RH: Asthma: an epidemic of dysregulated immunity. Nat Immunol 3: 715-720, 2002.

3. Maddox L and Schwartz DA: The pathophysiology of asthma. Annu Rev Med 53: 477-498, 2002.

4. Wills-Karp M: Immunologic basis of antigen-induced airway hyperresponsiveness. Annu Rev Immunol 17: 255-281, 1999.

5. Coyle AJ, Le Gros G, Bertrand C, et al: Interleukin-4 is required for the induction of lung Th2 mucosal immunity. Am J Respir Cell Mol Biol 13: 54-59, 1995.

6. Gavett SH, Chen X, Finkelman F and Wills-Karp M: Depletion of murine $\mathrm{CD}^{+} \mathrm{T}$ lymphocytes prevents antigen-induced airway hyperreactivity and pulmonary eosinophilia. Am J Respir Cell Mol Biol 10: 587-593, 1994.

7. Hogan SP, Koskinen A and Foster PS: Interleukin-5 and eosinophils induce airway damage and bronchial hyperreactivity during allergic airway inflammation in BALB/c mice. Immunol Cell Biol 75: 284-288, 1997

8. Henderson WR Jr, Chi EY and Maliszewski CR: Soluble IL-4 receptor inhibits airway inflammation following allergen challenge in a mouse model of asthma. J Immunol 164: 1086-1095, 2000.

9. Hamelmann E, Oshiba A, Loader J, et al: Antiinterleukin-5 antibody prevents airway hyperresponsiveness in a murine model of airway sensitization. Am J Respir Crit Care Med 155: 819-825, 1997.

10. Broide DH, Paine MM and Firestein GS: Eosinophils express interleukin 5 and granulocyte macrophage-colony-stimulating factor mRNA at sites of allergic inflammation in asthmatics. J Clin Invest 90: 1414-1424, 1992.

11. Desreumaux P, Janin A, Dubucquoi S, et al: Synthesis of interleukin-5 by activated eosinophils in patients with eosinophilic heart diseases. Blood 82: 1553-1560, 1993.

12. Woerly G, Lacy P, Younes AB, et al: Human eosinophils express and release IL-13 following CD28-dependent activation. J Leukoc Biol 72: 769-779, 2002.

13. Bandeira-Melo C, Sugiyama K, Woods LJ and Weller PF: Cutting edge: eotaxin elicits rapid vesicular transport-mediated release of preformed IL-4 from human eosinophils. J Immunol 166: 4813-4817, 2001.

14. Liu Z, Liu Q, Hamed H, et al: IL-2 and autocrine IL-4 drive the in vivo development of antigen-specific $\mathrm{Th} 2 \mathrm{~T}$ cells elicited by nematode parasites. J Immunol 174: 2242-2249, 2005.

15. Xu WF, Ji YY, Wu YD, Lin GM, Ye M and Sun B: Roles of IL-4 and other factors in the trichosanthin-induced ovalbuminspecific IgE response. Acta Pharmacol Sin 22: 736-740, 2001.
16. Lopez AF, Sanderson CJ, Gamble JR, Campbell HD, Young IG and Vadas MA: Recombinant human interleukin 5 is a selective activator of human eosinophil function. J Exp Med 167: 219-224, 1988.

17. Clutterbuck EJ, Hirst EM and Sanderson CJ: Human interleukin-5 (IL-5) regulates the production of eosinophils in human bone marrow cultures: comparison and interaction with IL-1, IL-3, IL-6, and GMCSF. Blood 73: 1504-1512, 1989.

18. Foster PS, Hogan SP, Ramsay AJ, Matthaei KI and Young IG: Interleukin 5 deficiency abolishes eosinophilia, airway hyperreactivity, and lung damage in a mouse asthma model. J Exp Med 183: 195-201,1996.

19. Huang SK, Xiao HQ, Kleine-Tebbe J, et al: IL-13 expression at the sites of allergen challenge in patients with asthma. J Immunol 155: 2688-2694, 1995.

20. Kopf M, Le Gros G, Bachmann M, Lamers MC, Bluethmann H and Kohler G: Disruption of the murine IL-4 gene blocks Th2 cytokine responses. Nature 362: 245-248, 1993.

21. McKenzie GJ, Emson CL, Bell SE, et al: Impaired development of Th2 cells in IL-13-deficient mice. Immunity 9: 423-432, 1998.

22. Rahman I, Morrison D, Donaldson K and MacNee W: Systemic oxidative stress in asthma, COPD, and smokers. Am J Respir Crit Care Med 154: 1055-1060, 1996.

23. Henricks PA and Nijkamp FP: Reactive oxygen species as mediators in asthma. Pulm Pharmacol Ther 14: 409-420, 2001.

24. Higa T and Ke B: Clinical and basic medical research on EMX. EMRO Okinawa, 2001.

25. Chui CH, Cheng GY, Ke B, et al: Growth inhibitory potential of effective microorganism fermentation extract (EM-X) on cancer cells. Int J Mol Med 14: 925-929, 2004.

26. Aruoma OI, Deiana M, Rosa A, et al: Assessment of the ability of the antioxidant cocktail-derived from fermentation of plants with effective microorganisms (EM-X) to modulate oxidative damage in the kidney and liver of rats in vivo: studies upon the profile of poly- and mono-unsaturated fatty acids. Toxicol Lett 135: 209-217, 2002

27. Deiana M, Dessi MA, Ke B, et al: The antioxidant cocktail effective microorganism X (EM-X) inhibits oxidant-induced interleukin-8 release and the peroxidation of phospholipids in vitro. Biochem Biophys Res Commun 296: 1148-1151, 2002.

28. Aruoma OI, Moncaster JA, Walsh DT, et al: The antioxidant cocktail, effective microorganism X (EM-X), protects retinal neurons in rats against N-methyl-D-aspartate excitotoxicity in vivo. Free Radic Res 37: 91-97, 2003.

29. Datla KP, Bennett RD, Zbarsky V, et al: The antioxidant drink effective microorganism-X (EM-X) pre-treatment attenuates the loss of nigrostriatal dopaminergic neurons in 6-hydroxydopamine-lesion rat model of Parkinson's disease. J Pharm Pharmacol 56: 649-654, 2004.

30. Yuan HC: EM-X as a free radical scavenger. Center for Condensed Matter Science, National Taiwan University, Taipei, 1999.

31. Hamelmann E, Schwarze J, Takeda K, et al: Noninvasive measurement of airway responsiveness in allergic mice using barometric plethysmography. Am J Respir Crit Care Med 156: 766-775, 1997.

32. Baraldi E, Ghiro L, Piovan V, et al: Increased exhaled 8-isoprostane in childhood asthma. Chest 124: 25-31, 2003.

33. Committee IEMCE: Proceedings of The 2nd International EM Medical Conference. IEMC Executive Committee Secretariat, Okinawa, 2003.

34. Wood LG, Garg ML, Simpson JL, et al: Induced sputum 8isoprostane concentrations in inflammatory airway diseases. Am J Respir Crit Care Med 171: 426-430, 2005.

35. Walker C, Virchow JC Jr, Bruijnzeel PL and Blaser K: T cell subsets and their soluble products regulate eosinophilia in allergic and nonallergic asthma. J Immunol 146: 1829-1835, 1991.

36. Robinson DS, Hamid Q, Ying S, et al: Predominant TH2-like bronchoalveolar T-lymphocyte population in atopic asthma. N Engl J Med 326: 298-304, 1992.

37. Rowe BH, Edmonds ML, Spooner CH, Diner B and Camargo CA Jr: Corticosteroid therapy for acute asthma. Respir Med 98: 275-284, 2004.

38. Nimmagadda SR, Spahn JD, Nelson HS, Jenkins J, Szefler SJ and Leung DY: Fluticasone propionate results in improved glucocorticoid receptor binding affinity and reduced oral glucocorticoid requirements in severe asthma. Ann Allergy Asthma Immunol 81: 35-40, 1998. 